eISSN 2582 - 0559

“An Official Journal of IDA - Madras Branch"C2019.

Available online

\title{
POST EXPOSURE PROPHYLAXIS IN DENTAL CLINICS- A REVIEW
}

\author{
Dr.J.Selvakumar, M.Rojadarshini \\ Department of Periodontology, \\ Madha Dental College and Hospital, Kundrathur, Chennai, Tamilnadu, India.
}

\begin{abstract}
Occupational exposures are common among dentists,

To access \& cite this article Website: jidam.idamadras.com

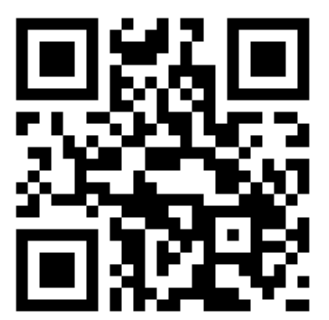
physicians and other health care professionals as they are in direct connection with blood and other body fluids. Accidental exposure to the blood borne pathogens Human Immunodeficiency Virus (HIV), Hepatitis B Virus (HBV) and Hepatitis $\mathrm{C}$ Virus (HCV) may occur through injury by sharp instruments and needles and exposure of mucous membrane to blood and other potentially infectious body secretions. This article deals about those who are at risk, factors that influence their risk, do's and don'ts of the exposed, their management and medications.
\end{abstract}

DOI:10.37841/jidam_2020_v7_i1_03
KEYWORDS: HIV, HBV, HCV, exposure, risk.

\footnotetext{
Address for correspondence:

Dr.J.Selvakumar., MDS.,

Professor and Head, Department of Periodontology,

Madha Dental College and Hospital, Kundrathur, Chennai,

Tamilnadu, India

Email id: dr.selvakumar@hotmail.com
}

Received - 20.12.2019

Accepted - 17.02.2020

Published - 27.03.2020 


\section{INTRODUCTION}

Post occupational exposure of health care workers to some blood-borne viral pathogens (HIV, HBV and HCV) is more common; occurrence and ways of minimizing/ preventing such exposures; and the need for Post Exposure Prophylaxis (PEP) after such exposure have been elaborated briefly.

In the occupational settings, there is a risk that health care professionals will be exposed to blood borne pathogens like Human Immunodeficiency Virus (HIV), Hepatitis-B Virus (HBV) and Hepatitis-C Virus (HCV) during working hours.

An exposure that may place a Health Care Professional at risk of blood-borne pathogens are mostly due to:

$\checkmark \quad$ A percutaneous injury (eg; needle stick or cut with a sharp instrument)

$\checkmark$ Contact with mucous membrane of the eye or mouth

$\checkmark$ Contact with non-intact skin (particularly when the exposed skin is chapped, abraded, afflicted with dermatitis)

$\checkmark$ Contact with the intact skin when the contact duration is prolonged (eg: several minutes or more)

$\checkmark$ With blood or other potentially infectious body fluids. ${ }^{1,2}$

\section{WHO ARE AT RISK?}

Professionals with frequent blood exposures include dentists, nursing staff and students, physicians, surgeons, emergency care providers, labor and delivery room personnel, laboratory technicians and health facility cleaning staff.

Fluids such as blood, semen, vaginal secretions, cerebrospinal fluid, synovial fluid, pleural fluid, peritoneal fluid, pericardial fluid, amniotic fluid or other body fluids that are contaminated with visible blood are at risk of exposure to the virus more frequently. Faeces, nasal secretions, saliva, sputum, sweat, urine, tears and vomits are not potentially infectious, unless visibly contaminated with blood. ${ }^{1,2,3}$

Transmission through intact skin contact are not yet documented. Any direct contact of virus without any barrier requires clinical evaluation.

\section{FACTORS THAT INFLUENCE RISK OF INFECTION:}

Various studies have shown that the risk of infection varies with the type of exposure:

$>$ Type of needle (hollow bore vs solid)

$>$ Device visibly contaminated with patient's blood

$>$ Depth of injury

$>$ Amount of blood involved in the exposure
$>$ Amount of virus in the exposed blood or fluid at the time of exposure

$>$ Timely ( $<2 \mathrm{hrs}$ and upto $72 \mathrm{hrs}$ ) availability and efficacy of the Post exposure prophylaxis.

On an average, among dentists, prevalence rate of HIV infection is low compared to HBV and HCV infection. $2,3,4,5$

COMMON ROUTES OF EXPOSURE ARE: ${ }^{6,7,8,9,10,15,16}$

NOTE: Needle-stick exposure for $\mathrm{HBV}$ is $9-30 \%$ and for $\mathrm{HCV}$ is $1-10 \%^{17,18}$

\begin{tabular}{|l|l|}
\hline EXPOSURE ROUTE & HIV \\
\hline Blood transfusion & $90-95 \%$ \\
\hline Perinatal & $20-40 \%$ \\
\hline Sexual intercourse & $0.1 \%-10 \%$ \\
\hline Vaginal & $0.05 \%-0.1 \%$ \\
\hline Anal & $0.065 \%-0.5 \%$ \\
\hline Oral & $0.005 \%-0.01 \%$ \\
\hline Injecting drugs use & $0.67 \%$ \\
\hline Needle stick exposure & $0.3 \%$ \\
\hline $\begin{array}{l}\text { Mucous membrane splash to } \\
\text { eye, oral and nose }\end{array}$ & $0.09 \%$ \\
\hline
\end{tabular}

DO'S and DONT'S for the exposed individuals:

DO'S:

$\square$ Stay calm

口 Remove gloves, if appropriate

- Wash exposed site thoroughly with running water, if splashes have gone into the eyes or mouth

$\square$ Consult the designated physician/personnel immediately as per institutional guidelines, for the management of the occupational exposure

DONT'S:

$\square$ Do not panic

Do not contact the wound

Do not squeeze blood from wound

Do not use bleach, alcohol, iodine, antiseptic. ${ }^{1,2}$

\section{Reduction of the risk of infection:}

Guidelines formulated/published by the CDC (Centre for Disease Control), known as the standard precautions (1996; formerly universal precautions, 1987) should be followed for handling blood and body fluids including all secretions and excretions (serum, semen, vaginal secretion) by all health care professionals at all times. As the prevention of exposure to virus remains the mainstay of occupational infection prevention, some of these simple procedures can limit its exposure and reduce the risk of infection. $^{3,11}$ 

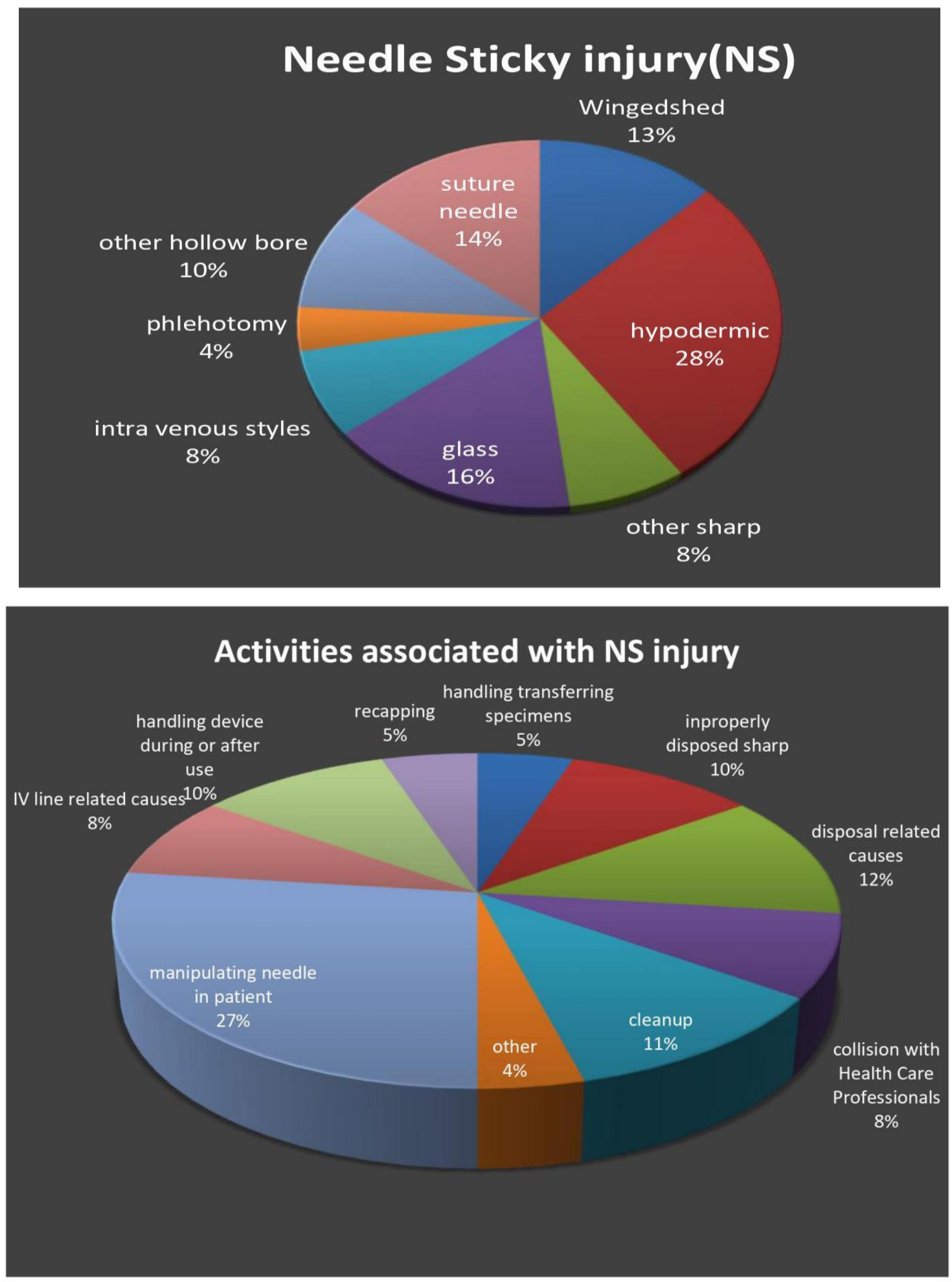

The Essentials of Standard Precautions and Safe Laboratory Practices:

$>$ Blood, blood products, all body fluids, and materials contaminated are considered as infections for $\mathrm{HIV}, \mathrm{HBV}, \mathrm{HCV}$ and other blood borne pathogens.
$>$ Use appropriate barrier precautions to prevent exposure to skin and mucous membranes.

$>$ Wear gloves, gowns/aprons, masks, and goggles, while handling all potentially infectious material

$>$ Take special care of handling sharp objects (like needles, lancets, scalpels, etc.) to avoid injuries.

$>$ Avoid unnecessary use of sharp instruments and needles

$>$ Disposable needles should be used 
> Handle hollow bore needles with care as it may lead to deep injuries

$>\quad$ Never recap needles

$>$ Never break/bend needles by hand

$>$ Needles/sharp instruments should not be left on trolleys and bedside tables and must be disposed off immediately

$>$ Never pass used sharp instruments from one person to another directly

$>$ Dispose sharp instruments in a puncture resistant container containing one percent sodium hypochlorite solution

$>$ Wash hands with water and soap after removing gloves, handling infectious materials, before leaving the laboratory area, and immediately after any contamination of skin surfaces.

$>\quad$ Work surfaces should be decontaminated with 0.1 percent sodium hypochlorite solution.

$>$ Laboratory personnel should refrain from mouth pipetting, eating, drinking, or smoking in the work area.

$>$ Access to the laboratory should be limited to trained personnel only. Food and drink must be stored in refrigerators in areas other than the work area.

$>\quad$ All Health Care Professionals must be immunized against $\mathrm{HBV}^{8}$

\section{POST EXPOSURE MANAGEMENT}

Steps to be followed the accidental exposure to blood/other potentially infectious materials:

1. First aid

2. Risk assessment

3. Informed consent and counselling

4. Decision on prophylactic treatment for HIV and HBV

5. Monitoring and follow-up of HIV, HBV, and HCV status

6. Documentation of exposure $12,13,14,16$

\section{FIRST AID}

\section{Management of Exposed Site}

For skin: If the skin is broken by a prick from needle stick or sharp instrument, immediately wash the wound and surrounding skin with water and soap, and rinse.

- Do not scrub.

- Do not use antiseptics or skin washes (e.g., bleach, chlorine, alcohol).

- Wash the area immediately after a splash of blood or bodily fluid on unbroken skin.

For the eye: Immediately irrigate the exposed eye thoroughly with water or normal saline.

- If wearing contact lenses, leave them in place while irrigating.

- Once the eye is cleaned, remove the contact lens and clean them in a normal manner.

- Do not use soap or disinfectant on the eye.

For mouth: Spit fluid out immediately. Rinse the mouth thoroughly using water or saline and spit again.

- Repeat the process several times.

- Do not use soap or disinfectant in the mouth.

*The exposure must be reported immediately to the concerned authority.

\section{ASSESSMENT OF RISK}

- A designated person/trained doctor must assess the risk of $\mathrm{HIV}$ and $\mathrm{HBV}$ transmission following an accidental exposure to blood (AEB).

- This assessment must be quick to start treatment/prophylaxis without any delay.

- After an AEB (for percutaneous exposure), an HIV seroconversion rate of 0.3 percent is an average rate.

- The risk of infection transmission is proportional to the amount of HIV transmitted, which depends on the nature of exposure and the status of the source patient. $12,13,14,16$

\section{ASSESSING THE NATURE OF RISK:}

\begin{tabular}{|c|c|}
\hline CATEGORY & $\begin{array}{l}\text { DEFINITION } \\
\text { EXAMPLE }\end{array}$ \\
\hline MILD EXPOSURE & $\begin{array}{l}\text { Mucus membrane/non-intact } \\
\text { skin with small volume, e.g., } \\
\text { a superficial wound (erosion } \\
\text { of the epidermis) with a } \\
\text { plain or low caliber needle; } \\
\text { contact with the eyes or } \\
\text { mucous membranes; } \\
\text { subcutaneous injection } \\
\text { following small bore needles }\end{array}$ \\
\hline MODERATE EXPOSURE & $\begin{array}{l}\text { Mucus membrane/non-intact } \\
\text { skin with large volumes or } \\
\text { percutaneous superficial } \\
\text { exposure with solid needle } \\
\text { (e.g., a cut or needle stick } \\
\text { injury penetrating gloves). }\end{array}$ \\
\hline SEVERE EXPOSURE & $\begin{array}{l}\text { Percutaneous with large } \\
\text { volume, e.g., an } \\
\text { accident with wide bore } \\
\text { needle (>18G) visibly } \\
\text { contaminated with } \\
\text { blood; a deep wound } \\
\text { (haemorrhagic wound } \\
\text { and/or very painful); } \\
\text { transmission of a } \\
\text { significant volume of } \\
\text { blood; an accidental } \\
\text { injury with material, } \\
\text { which has previously } \\
\text { been used intravenously } \\
\text { or intra-arterially }\end{array}$ \\
\hline
\end{tabular}

ASSESSING THE STATUS OF RISK:

Assessing the status of the patient or object ${ }^{12,13,14,16}$ 


\begin{tabular}{|l|l|}
\hline HIV STATUS & DEFINITION \\
\hline HIV NEGATIVE & $\begin{array}{l}\text { Source is not HIV infected } \\
\text { (but consider HBV and } \\
\text { HCV) }\end{array}$ \\
\hline LOW RISK & $\begin{array}{l}\text { HIV positive and clinically } \\
\text { asymptomatic }\end{array}$ \\
\hline HIGH RISK & $\begin{array}{l}\text { HIV positive and clinically } \\
\text { symptomatic }\end{array}$ \\
\hline UNKNOWN RISK & $\begin{array}{l}\text { Status of the patient is } \\
\text { unknown and neither the } \\
\text { patient nor his/her blood is } \\
\text { available for testing }\end{array}$ \\
\hline
\end{tabular}

\section{INFORMED CONSENT AND COUNSELLING}

Almost every person feels anxious after exposure. They should be counselled, and psychological support must be provided. They should be informed about the Post Exposure Prophylaxis.

Exposed persons should receive appropriate information about the risks and benefits of Post Exposure Prophylaxis medications. It should be clear that Post Exposure Prophylaxis is not mandatory. Exposed persons should, however, be made to understand that a few cases of transmission have been seen in cases given prophylaxis.

Documentation of exposure is essential. For prophylactic treatment the exposed person must sign a consent form. Informed consent also means that if exposed, the person has been advised on Post Exposure Prophylaxis. If the individual refuse to initiate Post Exposure Prophylaxis, it should be documented. The designated officer for Post Exposure Prophylaxis should keep this document. An information sheet covering the Post Exposure Prophylaxis and the biological follow-up after any AEB must be given to the person under treatment. ${ }^{11}$

\section{DECISION ON PROPHYLACTIC TREATMENT FOR HIV AND HBV}

\section{Medications and regimens:}

Because Post Exposure Prophylaxis has its greatest effect if started within 2 hours of exposure it is essential to act immediately. Ideally, therapy should be started within 2 hours and or atleast within 72 hours of exposure. Never delay the treatment. Re-evaluation is to be done after 72 hours of the exposure. If the risk is known to be insignificant, Post Exposure Prophylaxis should be discontinued, if the medication is already started. People who are known to be HIV positive should not receive Post Exposure Prophylaxis. Type of exposure and the HIV status of the exposed individual decides the type of regimen to be started (given in table below)

Dosages of the drugs for post exposure prophylaxis for adults and adolescents- Fixed Dose Combination of Tenofovir (TDF) $300 \mathrm{mg}$ plus Lamivudine (3TC) $300 \mathrm{mg}$ plus Efavirenz (EFV) $600 \mathrm{mg}$ once daily for 4 weeks. If the person is already on Antiretroviral Therapy, start the exposed person the above-mentioned regimen at the earliest with proper counselling and then refer for an expert opinion $9,10,13,19$

\begin{tabular}{|c|c|c|c|}
\hline EXPOSURE & $\begin{array}{l}\text { HIV+ AND } \\
\text { ASYMPTOM } \\
\text { ATIC }\end{array}$ & $\begin{array}{l}\text { HIV+ AND } \\
\text { CLINICALLY } \\
\text { SYMPTOMATIC }\end{array}$ & $\begin{array}{l}\text { HIV STATUS } \\
\text { UNKNOWN }\end{array}$ \\
\hline MILD & $\begin{array}{l}\text { Consider 2- } \\
\text { drug Post } \\
\text { Exposure } \\
\text { Prophylaxis }\end{array}$ & $\begin{array}{l}\text { Start 2-drug } \\
\text { Post Exposure } \\
\text { Prophylaxis }\end{array}$ & $\begin{array}{l}\text { Consider 2- } \\
\text { drug Post } \\
\text { Exposure } \\
\text { Prophylaxis } \\
\text { OR } \\
\text { No Post } \\
\text { Exposure } \\
\text { Prophylaxis }\end{array}$ \\
\hline MODERATE & $\begin{array}{l}\text { Start 2-drug } \\
\text { Post } \\
\text { Exposure } \\
\text { Prophylaxis }\end{array}$ & $\begin{array}{l}\text { Start } 3 \text {-drug } \\
\text { Post Exposure } \\
\text { Prophylaxis }\end{array}$ & $\begin{array}{l}\text { Consider 2- } \\
\text { drug Post } \\
\text { Exposure } \\
\text { Prophylaxis } \\
\text { or No Post } \\
\text { Exposure } \\
\text { Prophylaxis }\end{array}$ \\
\hline SEVERE & $\begin{array}{l}\text { Start 3-drug } \\
\text { Post } \\
\text { Exposure } \\
\text { Prophylaxis }\end{array}$ & $\begin{array}{l}\text { Start 3-drug } \\
\text { Post Exposure } \\
\text { Prophylaxis }\end{array}$ & $\begin{array}{l}\text { Consider 2- } \\
\text { drug Post } \\
\text { Exposure } \\
\text { Prophylaxis } \\
\text { or No Post } \\
\text { Exposure } \\
\text { Prophylaxis }\end{array}$ \\
\hline
\end{tabular}

An expert or physician opinion is to be seeked in case if there is any delay in reporting the exposure., if the source is unknown. If the person is known or suspected to be pregnant or the breastfeeding mothers (initiate PEP) or if the source patient is on Anti Retroviral Therapies or if the source is toxic to Post Exposure Prophylaxis.

IF SOURCE PATIENT IS ON ART the physician should consider the risk by the exposure; history of the source and clinical response to ARTs; decreased CD4 count; viral load measurement and the current stage of the disease. If the source is known to be drug resistant (drugs considered for PEP regimen) then an alternative drug regimen is to be prescribed as per expert's opinion.

PREGNANCY AND POST EXPOSURE PROPHYLAXIS: If the exposed individual is known to be pregnant or suspected to be, at the time of exposure then she must get the regimen primarily as of non-pregnant individuals. They are to be given antiretroviral chemoprophylaxis, if needed. The authority must be consulted about the use of ARTs for the post exposure management of the individual. For all the female considering post exposure prophylaxis, pregnancy test is recommended in case of doubt.

SIDE EFFECTS AND ADHERENCE TO POST EXPOSURE PROPHYLAXIS: Side effects most commonly like nausea and fatigue are more commonly indicated in Health Care Professionals taking Post Exposure Prophylaxis than People Living with HIV/AIDS taking ARTs. Side 
effects are more common at the initial stage of treatment and includes nausea, fatigue and muscular pain. The respective individual under treatment is to be informed about the side effects caused and to be dissuaded from stopping the treatment. Anaemia/ leukopenia/thrombocytopenia may also occur. Side effects are mild and transient.

Adherence information and psychological support are essential. More than $95 \%$ adherence is important to maximize the efficacy of the medication in Post Exposure Prophylaxis. Side effects can be treated by medications. Complete blood count test and liver function test are to be performed at the beginning of the treatment and after 4 weeks $^{9,10,13,19}$.

\section{POST EXPOSURE PROPHYLAXIS (PEP) FOR HBV AND HCV INDIVIDUALS:}

PEP regimen against $\mathrm{HBV}$ individual depends upon the HBV status, type of exposure and the previous immunization status of the individual.

\section{MANAGEMENT OF POST EXPOSURE PROPHYLAXIS FOR HBV AND HCV INDIVIDUALS:}

There is no specific PEP regimen for HCV exposed individuals. For HBV individuals, the response of the person depends on his or her immune status and are determined by the history of the HBV vaccine and its response. ${ }^{14,17,18,19}$ HBV Post Exposure Prophylaxis is safe for pregnant ladies and breast-feeding mothers

\section{MONITORING AND FOLLOW-UP OF HIV, HBV AND HCV STATUS}

Follow up of exposed HCPs:

Long term follow up, counselling, and education ${ }^{14,17,18,19}$

- Testing for at least 6 months after exposure (6 weeks, 12 weeks and 6 months)

If PEP is used: drug toxicity monitoring at base line and after 2 weeks.

Specific steps taken to reduce the risk of infection for HBV individual are:

\begin{tabular}{|l|l|}
\hline HBV IMMUNE STATUS & $\begin{array}{l}\text { POST EXPOSURE } \\
\text { PROPHYLAXIS }\end{array}$ \\
\hline Unvaccinated & HBV vaccination and HbIg \\
\hline $\begin{array}{l}\text { Previously vaccinated, } \\
\text { known responder (Anti- } \\
\text { hepatitis B surface antigen } \\
\text { positive) }\end{array}$ & None \\
\hline $\begin{array}{l}\text { Previously vaccinated, } \\
\text { known non-responder }\end{array}$ & HBV vaccination and HbIg \\
\hline $\begin{array}{l}\text { Antibody response unknown } \\
: \text { Test; if antibody response } \\
\text { is < } 10 \text { IU/ml, }\end{array}$ & HBV vaccination and HbIg \\
\hline
\end{tabular}

- Pre-test counselling is to be provided and Post Exposure Prophylaxis should be started as mentioned above.,
Before starting PEP, 3-5ml of the person's baseline blood sample is to be taken and sent to lab for testing and storage. Serum sample is to be collected as soon as possible after exposure for HIV testing. Otherwise, it may be difficult to attribute the infection acquired. The first sample for HIV testing is collected immediately after exposure, the $2^{\text {nd }}$ at 6 weeks, the $3^{\text {rd }}$ at 12 weeks, and the last at 6 months after exposure.

- During the follow-up period, especially the first 6-12 weeks, the following measures are to be adopted by the Health Care Professionals: refraining from blood, semen, organ donation and abstinence from sexual intercourse.

- In case, sexual intercourse is undertaken, a latex condom must be used to reduce the risk of HIV transmission. Women should not breast feed their infants.

- The exposed person is advised to seek medical evaluation for any febrile illness that occurs within 12 weeks of exposure. ${ }^{14,17,18,19}$

\section{DOCUMENTATION OF EXPOSURE}

The exposure report details should include:

- Date, time, and place of exposure

- Type of procedure done

- Type of exposure: percutaneous, mucus membrane, etc.

- Duration of exposure: Exposure source and volume; type of specimen involved ${ }^{14,17,18,19}$

All persons must be informed about the immediate exposure to initiate the preventive care in time to be effective and casual approach may lead to casualty.

\section{CONCLUSION}

If transmission of a blood-borne infection occurs after occupational exposure, it should be documented, and the Health Care Professionals should be treated. If exposure occurs, immediate care for the exposed part and the person is to be done and it should be documented and reported. Then, the appropriate PEP medication regimens after the proper assessment of such exposure must be started. Counseling is to be given, if indicated as per the national guidelines and subsequent follow-up would be beneficial.

For the management of such occupational exposures, each hospitallclinic should have an infection control team and policy arrangements for the prompt and uninterrupted (round the clock) supply of PEP drugs as per national guidelines. All Health Care Professionals should be vaccinated against Hepatitis B.

Such exposures can be minimized by Health Care Professionals following standard precautions at all times; by treating all patients/specimens as potentially infectious; by avoiding unnecessary invasive intervention wherever possible; by using appropriate barriers and Personal Protection Equipment to prevent exposure to blood and body fluids; through the safe handling of sharps and their proper disposal to avoid injuries; by thoroughly washing hands after 
removing gloves; and by properly disinfecting work places and sterilizing used up articles, etc.

\section{FINANCIAL SUPPORT AND SPONSORSHIP:}

Nil

\section{CONFLICTS OF INTEREST:}

There are no conflicts of interest.

\section{REFERENCES}

1. Post-exposure prophylaxis to prevent HIV infection: joint WHO/ILO guidelines on postexposure prophylaxis (PEP) to prevent HIV infection. Geneva: World Health Organization; 2007. [18 November 2014].

2. Colour atlas of oral manifestations of AIDS; Sol silverman, jr.,Mosby publications, 1996

3. CDC, Updated guidelines for antiretroviral postexposure prophylaxis after sexual, injection drug use, or other nonoccupational exposure to HIV-United States, 2016,

4. Dental management of patients with HIV; Editor Michael Glick, Quintessence publishing co., inc., 1994

5. Emerging infections disease -hand book for dental surgeons - Indian Dental Association- CDE wing :1997

6. Consolidated guidelines on the use of antiretroviral drugs for treating and preventing HIV infection: recommendations for a public health approach. Geneva: World Health Organization; 2013. [18 November 2014].

7. Young TN, Arens FJ, Kennedy GE, Laurie JW, Rutherford GW. Antiretroviral post-exposure prophylaxis (PEP) for occupational HIV exposure. Cochrane Database Syst Rev. 2007;(1) CD002835.

8. Benn P, Fisher M, Kulasegaram R., on behalf of the BASHH, PEPSE Guidelines Writing Group Clinical Effectiveness Group. UK guideline for the use of post-exposure prophylaxis for HIV following sexual exposure (2011). Int J STD AIDS. 2011;22:695-708

9. Tan DH, Goddey-Erikefe B, Yoong D. Selecting an antiretroviral regimen for human immunodeficiency virus postexposure prophylaxis in the occupational setting. Infect Control Hosp
Epidemiol Off J Soc Hosp Epidemiol Am. 2014;35:326-8

10. Tosini W, Muller P, Prazuck T, Benabdelmoumen G, Peyrouse E, Christian B, et al. Tolerability of HIV postexposure prophylaxis with tenofovir/emtricitabine and lopinavir/ritonavir tablet formulation. AIDS Lond Engl. 2010;24:2375-80.

11. Bentz L, Enel P, Dunais B, Durant J, Poizot-Martin I, Tourette-Turgis C, et al. Evaluating counseling outcome on adherence to prophylaxis and followup after sexual HIV-risk exposure: a randomized controlled trial. AIDS Care. 2010;22:1509-16.

12. Swotinsky RB, Steger KA, Sulis C, Snyder S, Craven DE. Occupational exposure to HIV: experience at a tertiary care center. J Occup Environ Med. 1998;40:1102-9.

13. Nuesch R, Ananworanich J, Srasuebkul P. Interruptions of tenofovir/emtricitabine-based antiretroviral therapy in patients with HIV/hepatitis B virus co-infection. AIDS. 2008;22:152-4

14. Dore GJ, Soriano V, Rockstroh J, Kupfer B, Tedaldi E, Peters L, et al. Frequent hepatitis B virus rebound among HIV-hepatitis B virus-coinfected patients following antiretroviral therapy interruption. AIDS. 2010;24:857-65.

15. De Waal N, Rabie H, Bester R, Cotton MF. Mass needle stick injury in children from the Western Cape. J Trop Pediatr. 2006;52:192-6.

16. Ford N, Irvine C, Doherty M, Vitoria M, Baggaley R, Shubber Z. Do starter packs improve outcomes for people taking HIV post-exposure prophylaxis?; Poster presentation TUPE155. 20th International AIDS Conference; Melbourne, Australia. 20-25 July 2014;

17. Hepatitis B. Geneva: World Health Organization; 2014.

18. Guidelines for the screening, care and treatment of persons with hepatitis C infection. Geneva: World Health Organization; 2014.

19. Burty C, Pavel S, Ghomari K, Vermersch A, Christian B, Pouaha J, et al. Tolerability of fosamprenavir/ritonavir associated with zidovudine-lamivudine used as postexposure prophylaxis for HIV infection. J Acquir Immune Defic Syndr. 2008;49:334-6. 